\title{
OUTCOME OF PAEDIATRIC CATARACT SURGERY AT TILGANGA INSTITUTE OF OPHTHALMOLOGY, NEPAL
}

\author{
Gurung $R L^{1^{*}}$, Adhikari $S^{2}$, Shrestha $U D^{2}$, Ruit $S^{3}$
}

\section{Affiliation}

1. Consultant, Vitreo-Retina, Biratnagar Eye Hospital, Biratnagar

2. Associate Prof, Tilganga Institute of Ophthalmology, National Academy of Medical Sciences

3. MD, FRACO, Prof., National Academy of Medical sciences, Executive Director, Tilganga Institute of Ophthalmology

\section{ARTICLE INFO \\ Article History \\ Received : 16 January, 2018 \\ Accepted : 25 March, 2018 \\ Published : 30 April, 2018}

(C) Authors retain copyright and grant the journal right of first publication with the work simultaneously licensed under Creative Commons Attribution License CC - BY 4.0 that allows others to share the work with an acknowledgment of the work's authorship and initial publication in this journal.

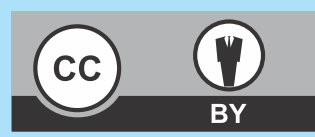

\section{ORA 50}

DOI: http://dx.doi.org/10.3126/bjhs.v3i1.19730

\author{
* Corresponding Author \\ Dr. Rajya Laxmi Gurung \\ Vitreo-Retina Consultant \\ Biratnagar Eye Hospital, Biratnagar \\ Email : rajya82@yahoo.com \\ https://orcid.org/0000-0003-0816-982
}

\section{ABSTRACT}

\section{Introduction}

Paediatric cataract and aphakia are still a major cause of childhood blindness in developing world due to lack of advanced technology. In developing countries like Nepal, many children still present late due to lack of awareness and financial constraints.

\section{Objectives}

The objective of this study was to determine the outcome of paediatric cataract surgery in a tertiary eye care centre in Nepal.

\section{Methodology}

A hospital based prospective, observational study taking 42 patients ( 77 eyes) aged $\leqq 15$ years diagnosed with paediatric cataract were enrolled during a period of 1 year ( Jan 2011 Jan 2012) at Tilganga Institute of Ophthalmology, Kathmandu, Nepal. The patients underwent either: a) Lens aspiration + Primary posterior capsulotomy (PPC) + Anterior Vitrectomy; b) Lens aspiration + PPC+ Anterior Vitrectomy + Intra-ocular lens (IOL); c) Lens Aspiration + IOL. Post-operatively optical \pm amblyopia correction. Statistical analysis was carried out by using STATA 9.0. The association of changes in the vision of eyes before and after surgery was analyzed by using generalization of McNemar's test (Stuart-Maxwell test). A pvalue of $<0.05$ was considered for the statistical significance. Institutional Ethics Board approval was obtained from the institutional review committee (IRC) of National Academy Medical Sciences ( NAMS ).

\section{Results}

Mean age of patients was 4.46 yrs \pm 4.32 (SD), range from (15 days -12 yrs); Male : Female: 22 (52\%)/20 (48\%); 35 $(83 \%)$ patients had bilateral cataract and $7(17 \%)$ had unilateral cataract. Morphologically, the most common type of cataract was total cataract (27/32\%). Post-operatively, a statistically significant improvement in vision was there in all the eyes ( $p$ value $:<0.0001$ ). Visual axis opacification was the most common post- operative complication seen in $20(26 \%)$ of total eyes by the end of 6 months.

\section{Conclusion}

Good visual outcome in paediatric cataract surgery can be obtained in developing countries like Nepal with minimal intra and post-op complications.

\section{KEYWORDS}

Aphakia, cataract, paediatric surgery 


\section{INTRODUCTION}

"Childhood blindness" describes a number of diseases and conditions that occur in childhood and early adolescence. ${ }^{1}$ It has been estimated that there are 1.4 million blind children in the world, 1 million of whom live in Asia and 300000 in Africa. ${ }^{2}$ Paediatric cataract is the leading cause of childhood blindness in developing countries.

Early detection and advanced surgical techniques have improved the prognosis of paediatric cataract in developed countriesbut because of the lack of advanced technology, paediatric cataract and aphakia are still a major cause of childhood blindness in developing world..$^{3-5}$

In countries like Nepal, a significant barrier to effective cataract surgery has been a lack of equipment, shortage of trained paediatric ophthalmologists and anaesthesiologists and the expense of advanced monitoring equipment due to which proper management of paediatric cataract is a serious challenge in Nepal. ${ }^{6,7}$ Thus to improve timely eye care of children, evidence-based information is very crucial especially when information regarding paediatric cataract in nepal are few and sketchy. Tilganga Institute of Ophthalmology ( TIO ) is one of the very few institutions in Nepal where paediatric cataract surgery is performed routinely under general anesthesia. In a way TIO has become a sort of referral centre, a representative of the country as a whole in terms of variety of ocular conditions. Thus this study was carried out to identify the visual outcome of childhood cataract surgery in a tertiary eye care centre in Nepal.

\section{METHODOLOGY}

This was a hospital based prospective, observational study done at Tilganga Institute of Ophthalmology, Kathmandu from Jan 2011 to Jan 2012. The patients were followed up for 6 months following surgery or till last follow up whichever was more. A total of 42 patients (77 eyes) were recruited for the study. All patients $\leq 15$ years diagnosed with paediatric cataract between 2011 to Jan 2012 were included in the study. Patients with traumatic cataract, complicated cataract, patients undergoing secondary IOL implantation were excluded from the study. Institutional Review Committee approval was obtained from National Academy Medical Sciences ( NAMS).

A standard protocol for evaluation of children with cataract was followed. A detailed history was taken from the parents/guardian comprising of chief complaint, age of presentation, history of trauma, drug use, ante-natal/ peri-natal history, systemic history, developmental milestone, immunization history, and any relevant family history.

Pre and Post-op best corrected visual acuity(VA) of each eye were examined using age appropriate tests ; For 0-3 yrs: CSM (Centre Steady Maintain), Preferential looking \{ Cardiff card, Teller Acuity\}; for 3-5 yrs: Light House symbols chart , Sheridan-Gardiner test and for age group $>5 \mathrm{yrs}$, Snellen's $\mathrm{E}$ chart were used.
Anterior segment examination and type of cataract was determined by using slit lamp bio-microscopy/ Kowa SL-15 portable handheld slit lamp or operating microscope under general anaesthesia. Fundus status was evaluated with indirect ophthalmoscope, using +20 D Volk lens or +90 D lens after dilatation with $1 \%$ tropicamide. Cycloplegic refraction was done whenever required. B-scan ultrasonography was done in cases of hazy media opacity obscuring the posterior view.

A detail pre-anaesthetic check up was done by qualified anaesthesiologist. All the surgeries were performed by two highly qualified paediatric ophthalmologists under general anaesthesia (GA). Informed consent was obtained for all patients from the parents/gaurdian after discussion of the risks, benefits and postoperative care.

The standard paediatric cataract surgery followed:

1 Lens aspiration + Primary Posterior Capsulotomy $(\mathrm{PPC})+$ Anterior Vitrectomy $(\mathrm{AV})$ for children $<2$ years old

2 Lens Aspiration + Primary Posterior Capsulotomy $(P P C)+$ Anterior Vitrectomy (AV) + IOL for children $\geq$ 2-8 years old

3. Lens Aspiration + Intra-ocular lens (IOL ) for children $>8$ years old

Under general anaesthesia, after cleaning and draping, bridle suture was applied. Then two limbal incisions were made utilizing a 20 gauge microvitreoretinal (MVR) knife at the 10 o'clock and 20 ' clock positions; one for an irrigation cannula connected to a balanced salt solution (BSS) and the other one for an aspiration/cutting hand piece. Anterior capsulotomy $5 \mathrm{~mm}$, either CCC (Continuous Curvilinear Capsulorrhexis) or a vitrectorhexis using a vitrector was done. The lens material was aspirated using a bimanual irrigation-aspiration technique with cutting rate of 150-300 cuts per minute and an aspiration maximum of 150-250. With a vitrectomy tip the posterior capsule was opened centrally (PPC 3-4 mm) and an anterior vitrectomy was performed. The posterior capsule was left intact in older children (> 8 yrs old). It was followed by implantation of IOL when desired,preferably in the bag, if not in the sulcus. No IOL was kept in children $<2$ yrs. Such children were planned for secondary IOL insertion once they reached 2 years of age. The IOL power was determined by A-scan biometry, either on operation theatre (OT) table or pre-operatively using SRK-II formula in co-operative children where keratometry was possible.

The IOL power inserted was:

a) $10 \%$ under-correction from age $2-8$ years.

b) Full emmetropic correction in children $>8$ years old 
At last the incision site was sutured with 80' vicryl suture.

In older children, after applying bridle suture, superior scleral tunnel was made, lens aspirated and IOL implanted through the tunnel. The tunnel was then closed water tight with 80 vicryl.

At the end of the procedure, all eyes received a subconjunctival injection of gentamicin and dexamethasone. The eye was patched and shield was placed over the eye. Children with bilateral congenital cataract underwent surgery for the second eye preferably within 1 week of surgery of the first eye. IOP was measured under GA when required using hand held Perkins tonometer .

Either, Polymethylmethacrylate (PMMA) lens or foldable lens, manufactured at the Tilganga Institute of Ophthalmology (TIO) Fred Hollows IOL factory, were implanted via scleral tunnel or clear corneal incisions respectively.

Any intra-operative complications whatsoever were recorded in the OT note by the operating surgeon or the assistant. Postoperatively, all eyes are given combination of topical steroids and antibiotics (predacetate / dexamethasone and ofloxacin/chloramphenicol) every 1 hourly for the first week then tapered accordingly depending on the inflammatory status of the eye. Patients were examined 1 day, 1 week, 2 weeks, 6weeks, 3 months and 6 months postoperatively.

In every visit, a detailed examination of the anterior and posterior segment and the possible complications were evaluated. VA was assessed using standard protocol described above at each follow up.

Patients were provided with optical corrections for any residual refractive errors 6 weeks after surgery. Likewise amblyopia management was done aggressively by either patching or atropinization.

If a patient was lost to follow up, his or her last recorded vision, and examination findings were taken as the final postoperative data.

The major outcome measure was final best corrected visual acuity (BCVA). Likewise, the various modes of presentation, age of presentation, morphology of cataract, types of surgeries performed, complications, need of optical correction, amblyopia management were also evaluated.

Postoperatively, the refractive status of the children was assessed by retinoscopy at 6 weeks after surgery and repeated thereafter at each visit thereafter. Near glasses were prescribed whenever required.

Statistical analysis was carried out using STATA 9.0. The association of different types of surgery with vision of eyes after surgery has been assessed by using Chi-square/ Fisher's exact test wherever applicable. Similarly, the association of changes in the vision of eyes before surgery and after surgery has been analyzed by using generalization of McNemar's test (Stuart-Maxwell test). A p-value of $<0.05$ is considered for the statistical significance.

\section{RESULTS}

A total of 42 patients (77 eyes) were recruited for the study of which 10 eyes were lost to follow up of which 67 eyes completed the study. Seven (17\%) patients had unilateral and 35 (83\%) patients had bilateral cataract. The distribution of males and females were almost equal 22 (52\%) male and $20(48 \%)$ female. The mean age of surgery in the current study was 4.46 years ( $S D \pm 4.32$ ); median was 3 years; range from 15 days ( 0.04 yrs) to 12 years. Total cataract 24 (34\%) and lamellar cataract 23 (29\%) were the most common types of cataract, followed by Nuclear 15 (19\%), Posterior subcapsular 4(5\%), Posterior polar 3 (4\%), Membranous 2(2\%). The other variants $3(7 \%)$ included 1 partially absorbed and 2 mixed cataracts. White pupillary reflex 50 (54\%) eyes was the most common presenting feature, followed by decreased vision 36 (39\%) eyes, strabismus 5(6\%) eyes and nystagmus 5 (1\%) eyes. Most of the patients 41 (56\%) eyes presented within 6 months of symptom, however $9(7 \%)$ eyes had late presentation after 5 years of onset of symptom. Most of the patients were in the visually impaired group <6/18 (Table 1). In patients in whom vision could be assessed only by fixation method, a significant percentage 17 (22\%) eyes were in the poor fixation group. Excluding the Fix and follow group, 53\% (19 of 36) were blind.

Table 1: Presenting Best Corrected Visual Acuity ( $n=77$

\begin{tabular}{|l|c|c|}
\hline Presenting BCVA & Frequency (eyes) & Percent \\
\hline $6 / 6-6 / 18$ & 2 & 3 \\
\hline$<6 / 18-6 / 60$ & 12 & 15 \\
\hline$<6 / 60-3 / 60$ & 3 & 4 \\
\hline$<3 / 60-P L$ & 19 & 25 \\
\hline Poor fix \& follow & 17 & 22 \\
\hline Good fix \& follow & 24 & 25 \\
\hline
\end{tabular}

Most of the eyes 40(64\%) underwent (Lens Aspiration + Primary Posterior Capsulotomy + Anterior Vitrectomy) followed by (Lens Aspiration + Primary Posterior Capsulotomy + Anterior vitrectomy + Intraocular lens implantation) in 20 (25\%) and (Lens Aspiration + Intraocular Lens) in 17(11\%) eyes. IOL was inserted in all bilateral cases aged 2 years and above. All unilateral cases irrespective of age were implanted with IOL. Except in 2 cases, IOL was kept in the bag. There was statistically significant improvement in BCVA post surgery in all vision group, $\mathrm{p}<0.0001$ (Table 2 ) . 
Table 2: Pre-surgery vs Post- surgery BCVA ( In all eyes, $n=77$ )

\begin{tabular}{|l|c|c|c|c|c|c|c|c|}
\hline $\begin{array}{c}\text { Pre-Surgery } \\
\text { BCVA }\end{array}$ & $\begin{array}{c}6 / 6-6 / 18 \\
(\text { Eyes/\%) }\end{array}$ & $\begin{array}{c}<6 / 18-6 / 60 \\
(\text { Eyes/\%) }\end{array}$ & $\begin{array}{c}<6 / 60-3 / 60 \\
(\text { Eyes/\%) }\end{array}$ & $\begin{array}{c}<3 / 60-P L \\
(\text { Eyes/\%) }\end{array}$ & $\begin{array}{c}\text { F \& F } \\
\text { (Eyes/\%) }\end{array}$ & $\begin{array}{c}\text { Poor F \& F } \\
\text { (Eyes/\%) }\end{array}$ & $\begin{array}{c}\text { Total } \\
\text { (Eyes/\%) }\end{array}$ & P-value* \\
\hline $6 / 6-6 / 18$ & $2(100 \%)$ & 0 & 0 & 0 & 0 & 0 & $2(100 \%)$ & \\
\hline$<6 / 18-6 / 60$ & $9(82 \%)$ & $1(9 \%)$ & 0 & $1(9 \%)$ & 0 & 0 & $11(100 \%)$ & \\
\hline$<6 / 60-3 / 60$ & $3(60 \%)$ & 0 & 0 & $2(40 \%)$ & 0 & 0 & $5(100 \%)$ \\
\hline$<3 / 60-P L$ & $9(70 \%)$ & 0 & $2(15 \%)$ & $2(15 \%)$ & 0 & 0 & $13(100 \%)$ & \\
\hline F\&F & 0 & 0 & 0 & 0 & $13(100 \%)$ & 0 & $13(100 \%)$ & \\
\hline PoorF \& F & 0 & 0 & 0 & 0 & $18(78 \%)$ & $5(22 \%)$ & $23(100 \%)$ & \\
\hline TOTAL & $23(34 \%)$ & $1(2 \%)$ & $2(3 \%)$ & $5(7 \%)$ & $31(47 \%)$ & $5(7 \%)$ & $67(100 \%)$ & 0.0001 \\
\hline
\end{tabular}

* McNemar's test (Stuart-Maxwell test)

All eyes ( $n=2$ / 100\%) which had pre-operative vision (6/6$6 / 18$ ) sustained same vision post-operatively. $82 \%$ eyes $(n=11)$ which had pre-operative vision $(<6 / 18-6 / 60)$ had improved vision (6/18-6/60) post-operatively. $60 \%$ eyes $(n=5)$ which had pre-operative vision $(<6 / 60-3 / 60)$ had improved vision (6/6-6/18). $70 \%$ eyes $(n=19)$ which had seen in 2 eyes (3\%). No serious complications like endophthalmitis, secondary glaucoma, retinal detachment were observed in any of the cases. All 77 eyes (100\%) were given optical correction from $6^{\text {th }}$ postoperative week. Amblyopia management was done in $7(9 \%)$ eyes. No anaesthesia related complications were noted.

Table 3 : Pre-operative and post-operative BCVA (In eyes where quantitative VA possible / $n=31$ )

\begin{tabular}{|c|c|c|c|c|c|c|}
\hline \multirow{2}{*}{ Pre-op VA } & \multicolumn{5}{|c|}{ Post Operative VA } & \multirow[b]{2}{*}{ P-Value* } \\
\hline & $\begin{array}{l}6 / 6-6 / 18 \\
\text { (eyes/\%) }\end{array}$ & $\begin{array}{c}<6 / 18-(6 / 60 \\
\text { eyes/\%) }\end{array}$ & $\begin{array}{c}<6 / 60-(3 / 60 \\
\text { eyes/\%) }\end{array}$ & $\begin{array}{l}<3 / 60-\mathrm{PL} \\
\text { (eyes/\%) }\end{array}$ & $\begin{array}{c}\begin{array}{c}\text { Total } \\
\text { (eyes/\%) }\end{array}\end{array}$ & \\
\hline $6 / 6-6 / 18$ & $2(100 \%)$ & 0 & 0 & 0 & $2(100 \%)$ & \\
\hline$<6 / 18-6 / 60$ & $9(82 \%)$ & $1(9 \%)$ & 0 & $1(9 \%)$ & $11(100 \%)$ & \\
\hline$<6 / 60-3 / 60$ & $3(60 \%)$ & 0 & 0 & $2(40 \%)$ & $5(100 \%)$ & \\
\hline$<3 / 60-P L$ & $9(70 \%)$ & 0 & $2(15 \%)$ & $2(15 \%)$ & $13(100 \%)$ & \\
\hline TOTAL & $23(74 \%)$ & $1(3 \%)$ & $2(7 \%)$ & $5(16 \%)$ & $31(100 \%)$ & $<0.0001$ \\
\hline
\end{tabular}

* McNemar's test (Stuart-Maxwell test)

pre-operative vision $(<3 / 60-\mathrm{PL})$ had post-operative vision (6/6-6/18). Taking only those eyes where quantitative vision assessment was possible: $74 \%$ of eyes $(n=31)$ had vision in the range of $(6 / 6-6 / 18) p:<0.0001$ (Table 3$)$. In the nonverbal group, $100 \%$ of eyes $(n=15)$ maintained good fixation post-operatively. No cases had any intra-operative complications.

Visual Axis Opacification (VAO) was not present at first follow up, however the number increased to $3(4 \%)$ on $2^{\text {nd }}$ week, $7(9 \%)$ on $6^{\text {th }}$ week, $14(18 \%)$ on $3^{\text {rd }}$ month and $20(26 \%)$ at 6 month follow up. None of the VAO required immediate intervention. Only one eye had Intra-oclular lens dislocation in the vitreous cavity on first post operative day for which immediate vitrectomy was done and the Intraocular lens implanted in sulcus. The final visual acuity in this eye was $6 / 9$. Likewise, one eye (1.29\%) had decentered IOL but it required no intervention. Pupillary capture was

\section{DISCUSSION}

Paediatric cataract surgery is only the first stage of a long, often complex rehabilitation process. Moreover, the cataract surgery itself is a specialized surgery requiring multidisciplinary approach involving anaesthesiologist, paediatrician, qualified paediatric ophthalmologist and optometrist.

The mean age of surgery in the current study was 4.46 years with SD \pm 4.32 range $(0.04-12)$ years; median 3 years. This is higher than what is reported in developed countries. ${ }^{2,8-10}$ However it is comparable to reports from developing world and within Nepal where the age of presentation is still delayed. ${ }^{6,11,12}$ As such, in the developed world, most childhood cataracts are diagnosed immediately following birth or even prenatally but late presentation, especially for congenital cataracts, is a matter of concern for developing countries, the main reason for late presentation being lack 
of awareness and poor socio-economic status. There was an almost equal distribution of males (52\%) and females $(48 \%)$ in this study. Indirectly it points out that girl child is given equal preference like male child even in developing countries like Nepal as well. There are reports from African/Asian countries regarding gender inequality in paediatric cataract surgery. The Danish study also shows rate of cataract surgery higher in boys than girls. ${ }^{13}$ In this study, a total of $83 \%$ of patients had bilateral presentation and only $27 \%$ had unilateral cataract. Increased ratio of bilateral cataract has been observed by other researches as well, a ratio of 3:1 reported by Johar et al. ${ }^{14}$ Interestingly a similar study done at TIO by Thakur et al showed 27 patients (31.8\%) had bilateral cataract and 58 (68.2\%), unilateral cataract, the possible reason might be due to inclusion of traumatic cataracts, which are most of the time unilateral. ${ }^{6}$ The commonest symptom of presentation in this study was white pupillary reflex (54\%) as has been reported by the Danish study and Shrestha UD. ${ }^{13,15}$ Interestingly nystagmus was in very few cases(1\%) and strabismus only in $6 \%$. Wilson et al have reported pre-op nystagmus $29.5 \%$ and pre-op strabismus $28 \%$, so compared to that study, $1 \%$ is very less which is a good sign because a positive nystagmus is a poor predictive sign of poorer outcome. ${ }^{16}$ In this study, the most common type of cataract was total (32\%) followed by lamellar (31\%). Wilson et al also showed total cataract $(68.5 \%)$ as the most common morphological variant. ${ }^{16}$ Similar reporting was done ( $50 \%$ total cataract ) in a study carried out in Nepal at TIO by Thakur et aland P. Gogate et al (39\%) in his study. ${ }^{6,17}$ However, studies done in Denmark has shown Nuclear cataract (36\%) as the most common morphological variant. ${ }^{13}$ This might be one of the reason for late presentation in developing countries like ours i.e unless the cataract is fully mature and white, it goes undetected. A considerable number of patients ( $56 \%$ eyes) in this study presented within 6 months of onset of symptoms. This is better than what has been reported in the other studies. A study done in West India by P. Gogate et al shows delay of up to 11 years. ${ }^{17}$ Delay in presentation has been a major issue for poor outcome in studies carried out within Nepal and outside. ${ }^{12,15,16,18-20}$ Unfortunately there is a large time lag between many children developing cataract and actually presenting for cataract surgery. ${ }^{20,21}$ The percentage of visually impaired is quiet high in this study (44\%), likewise in non-verbal group a considerable percentage (22\%) present with poor fixation and follow. This corresponds well with findings from other studies. Khandekar et al $^{21}$ found the best corrected presenting vision is $<3 / 60$ in (37.9\%) of eyes; P. Gogate et al found pre-operative best corrected vision was $<3 / 60$ in $(76.6 \%)$ eyes. ${ }^{17}$ Moreover recording visual acuity in children is a big challenge in young children. Inability to record visual status has been mentioned in other publications as well. ${ }^{22,23}$ In this study, the status of the visual acuity was difficult to assess in pre-verbal eyes of children below five years of age so had to resort to nonquantitative methods such as preferential looking method.
The low vision in this study has been seen more in the older age group ; visual acuity $<3 / 60$ in $55 \%$ of age group (11-15) years and in $50 \%$ of age group (6-10) years. This collaborates with similar finding from other studies. Study done by $P$. Gogate et al has shown preoperative best corrected vision was poorer for eyes with delayed presenting cataracts. ${ }^{17}$ All the surgeries in this study were carried under GA. A trained anaesthesiologist is available at TIO on regular basis and most of the paediatric surgeries were performed under GA. However, the problem of availability of general anaesthesia is still prevalent in many developing countries including Nepal. Operating on patients in rural settings with limited medical facilities and support leads to differences in how these cataracts are managed compared with accepted clinical approaches in the developed world. In this study primary IOL was inserted in $60 \%$ of eyes. Cases where IOL was inserted included all eyes more than 2 years old and unilateral cases of any age. Rest of $40 \%$ of eyes were planned for secondary IOL, once the child attained 2 years of age. In recent years primary IOL implantation is fast becoming the preferred modality of treatment for most children. The visual results in this study are encouraging. Nearly every patient in the current study showed improved visual acuity after surgery.

At the end of 6 months follow up, 74\% of eyes had best corrected vision in the range (6/6-6/18) and $86 \%$ had good preferential fixation. The proportion with good acuity after surgery is better than the figures of $44 \%$ reported by Yorston et al in Kenya, $48 \%$ by Yang et al in Taiwan and $44 \%$ by Basti et al. ${ }^{23,24}$ The result is comparable to that reported from series of similarly aged children from developed countries where proportions achieving 20/60 or better ranged from $72 \%$ to $91 \%$. $^{26-29}$ In our study, pre-surgery, 53\% eyes were blind whereas post surgery, $17 \%$ were blind. The $17 \%$ classified in the blind group also had improved vision with a good anatomical outcome in comparison to the pre-surgery vision. These were mostly unilateral cases with strabismus. Poor improvement in vision could be due to amblyopia. Amblyopia management was done in $7(9 \%)$ eyes. Both optical correction and (4-6) hours patching was done for amblyopia management. Of the 7 eyes, 5 were cases of unilateral cataract. It was very difficult to compare the visual outcome between unilateral vs bilateral cases from this study due to less no of sample size; there were only 7 unilateral cases in the current study. The reasons for quantitative acuity data being available in only approximately $47 \%$ of children are the use of non-quantitative methods in younger and noncooperative patients.This problem of assessing vision in very young and uncooperative children was seen in previous studies as well. ${ }^{29-31}$ Overall, post surgery there was statistically significant improvement in vision in all the eyes.

Post-operative complications associated with paediatric cataract surgery continue to be a major concern. The risk of post-operative complications is higher due to greater 
inflammatory response after paediatric cataract surgery. However, the frequency of post-operative complications were very less in this study till the 6 months follow up. Apart from one case of dislocated IOL in vitreous, no other serious complications were noted in this study. Visual axis opacification (VAO), seen in $26 \%$ of the total eyes $(n=77)$, was the most common post-operative complication seen, but till the 6 month follow up, none of the eyes required any intervention (Yag-capsulotomy or Surgical intervention ) for the opacification .

\section{CONCLUSION}

Timely management of paediatric cataract is very challenging in countries like Nepal. A statistically significant improvement in vision with minimal post-operative complications was seen in this study. This study demonstrates that good results can be obtained in developing countries like Nepal also.

\section{RECOMMENDATION}

More number of eyes need to be included in the study in order to make a comparison between primary vs secondary implantation of IOL and to make a comparison between unilateral and bilateral cataract cases.

\section{LIMITATIONS OF STUDY}

The assessment of visual acuity in children was very difficult especially in pre-verbal children. Moreover, the results in this study are drawn after a follow up period of only 6 months. This limits the precision of the study and our ability to draw meaningful conclusions.

\section{ACKNOWLEDGEMENTS}

The author would like to acknowledge Prof Shankar Khanal for data analysis.

\section{CONFLICTS OF INTEREST}

None

\section{REFERENCES}

1. Gilbert C. New issues in childhood blindness. Commun Eye Health J. 2001;14:53-56PPMID: 17491932.

2. Lambert SR, Lynn MJ, Reeves R, Plager DA, Buckley EG, Wilson ME. Is There a Latent Period for the Surgical Treatment of Children With Dense Bilateral Congenital Cataracts ? J AAPOS. 2006;10(1):30-6. DOI:10.1016/j.jaapos.2005.10.002.

3. Mwende J. Delay in presentation to hospital for surgery for congenital and developmental cataract in Tanzania. Br J Ophthalmol. 2005Jan;89(11):1478-82.PMID: 16234457 / DOI:10.1136/bjo.2005.074146.

4. Eriksen JR, Bronsard A, Mosha M, Carmichael D, Hall A, Courtright P. Predictors of Poor Follow-up in Children that had Cataract Surgery. Ophthalmic Epidemiol. 2006;13(4):237-43. DOI: 10.1080 /09286580600672213.

5. Bronsard A, Geneau R, Shirima S, Mwende J, Courtright P. Why are children brought late for cataract surgery? Qualitative findings from Tanzania. Ophthalmic Epidemiol. 2008;15: 383-8.DOI: 10. 1080/09286580802488624.

6. Thakur J, Reddy H, Wilson ME, Paudyal G, Gurung R, Thapa S, Tabin G, Ruit S. Pediatric cataract surgery in Nepal. J Cataract Refract Surg. 2004 Aug 31;30(8):1629-35. DOI: 10.1016/j.jcrs.2003.12.047.

7. Eckstein M, Vijayalakshmi P, Killedar M, Gilbert C, Foster A. Use of intraocular lenses in children with traumatic cataract in south India. BrJ Ophthalmol. 1998 Aug 1;82(8):911-5.PMID: 9828776.

8. Taylor D. Choice of surgical technique in the management of congenital cataract. Trans Ophthalmol Soc UK 1981;101(1):114-7. PMID: 6964215.

9. Keech RV, Tongue AC, Scott WE . Complications after surgery for congenital and infantile cataracts. Am J Ophthalmol 1989;108: 136-41 PMID: 2667370.

10. Astle WF, Alewenah O, Ingram AD, Paszuk A. Surgical outcomes of primary foldable intraocular lens implantation in children: understanding posterior opacification and the absence of glaucoma. J Cataract Refract Surg. 2009;35:1216-1222. DOI: 10.1016/j.jcrs. 2009.02.028.

11. Tomkins $\mathrm{O}$, Ben-Zion I, Moore DB, Helveston EE. Outcomes of pediatric cataract surgery at a tertiary care center in rural southern Ethiopia. JAMA Ophthalmol. 2011 Oct 10;129(10):1293-7. DOI: 10.1001/ archophthalmol.2011.268.

12. Adhikari S, Badhu BP, Bhatta NK, Jha CB, Baral N, Kumari N. Etiology and Clinical Profile of Pediatric Cataract in a Tertiary Care Center of Eastern Nepal: J Nepal Medical Association 2007;46 (167):94-98. PMID: 18274562.

13. Haargaard B, Wohlfahrt J, Fledelius HC, Rosenberg T, Melbye M. A nationwide Danish study of 1027 cases of congenital/infantile cataracts: etiological and clinical classifications. Ophthalmology. 2004 Dec 31;111(12):2292-8. DOI:10.1016/j.ophtha. 2004.06.024.

14. Johar SK, Savalia N, Vasavada A, Gupta P. Epidemiology based etiological study of pediatric cataracts in Western India. Indian J Med Sci. 2004 Mar 1;58(3):115. PMID: 15051906.

15. Shrestha UD. Postoperative follow up challenge in paediatric cataract surgery in Nepal. Journal of Nepal Paediatric Society. 2011 Sep 19;31(3):198-201. DOI : 10.3126/jnps.v31i3.4062.

16. Wilson ME, Hennig A, Trivedi RH, Thomas BJ, Singh SK. Clinical characteristics and early postoperative outcomes of pediatric cataract surgery with IOL implantation from Lahan, Nepal. J Pediatr Ophthalmol Strabismus. 2011 Sep 1;48(5):286-91.DOI: 10.3928 /01913913-20100920-03.

17. Gogate $P$, Khandekar R, Shrishrimal M, Dole K, Taras S, Kulkarni S, Ranade S, Deshpande M. Delayed presentation of cataracts in children: are they worth operating upon ? Ophthalmic Epidemiol. 2010 Feb 1;17(1):25-33. DOI:10.3109/0928 6580903450338.

18. Bronsard A, Geneau R, Shirima S, Courtright P, Mwende J. Why are children brought late for cataract surgery? Qualitative findings from Tanzania. Ophthalmic Epidemiol. 2008 Jan 1;15(6):383-8. DOI:10.1080/09286580802488624.

19. Angra SK. Etiology and management of congenital cataract. Indian J Pediatr. 1987 Sep 1;54(5):673-7.PMID: 3428985.

20. Mwende J, Bronsard A, Mosha M, Bowman R, Geneau R, Courtright $P$. Delay in presentation to hospital for surgery for congenital and developmental cataract in Tanzania. Br J Ophthalmol. 2005 Nov 1;89(11):1478-82. PMID: 16234457. 
21. Khandekar R, Sudhan A, Jain B, Shrivastav K, Sachan R. Pediatric cataract and surgery outcomes in Central India: a hospital based study.Indian J Med Sci. 2007 Jan 1;61(1):15. PMID: 17197734.

22. Congdon NG, Ruiz S, Suzuki M, Herrera V. Determinants of pediatric cataract program outcomes and follow-up in a large series in Mexico. J Cataract Refract Surg. 2007 Oct 31;33(10):1775-80. DOI:10.1016 /j.jcrs.2007.06.025.

23. Yorston D, Wood M, Foster A. Results of cataract surgery in young children in east Africa. Br J Ophthalmol. 2001 Mar 1;85(3):26771.PMID: 11222328.

24. Yang ML, Hou CH, Lee JS, Liang YS, Kao LY, Lin KK. Clinical characteristics and surgical outcomes of pediatric cataract in Taiwan. Graefes Arch Clin Exp Ophthalmol. 2006 Nov 1;244(11):1485-90.PMID: 16628419.

25. Basti S, Ravishankar U, Gupta S. Results of a prospective evaluation of three methods of management of pediatric cataracts. Ophthalmology. 1996 May 1;103(5):713-20. PMID: 8637679.

26. Koszewska-Kołodziejczak A, Kałuzny J. Visual acuity and binocular vision in children with pseudophakia. Klinika oczna. 2006;108(13):46-50. PMID: 16883940.
27. Gimbel HV, Basti S, Ferensowicz M, DeBroff BM. Results of bilateral cataract extraction with posterior chamber intraocular lens implantation in children. Ophthalmology. 1997 Nov 1;104(11): 1737-43. PMID: 9373100.

28. Peterseim MW, Wilson ME. Bilateral intraocular lens implantation in the pediatric population. Ophthalmology. $2000 \mathrm{Jul}$ 31;107(7):1261-6. PMID: 10889095.

29. Wilson ME, Elliott L, Johnson B, Peterseim MM, Rah SH, Werner L et al. AcrySof acrylic intraocular lens implantation in children: clinical indications of biocompatibility. J AAPOS. 2001 Dec 31;5(6):377-80. PMID: 11753259.

30. Chak M, Wade A, Rahi JS. Long-term visual acuity and its predictors after surgery for congenital cataract: findings of the British congenital cataract study. Invest Ophthalmol Vis Sci. 2006 Oct 1;47(10):4262-9. DOI:10.1167/iovs.05-1160.

31. Pavlovic S. Cataract surgery in children. Med Pregl 2000;53:257-61 PMID: 11089366. 